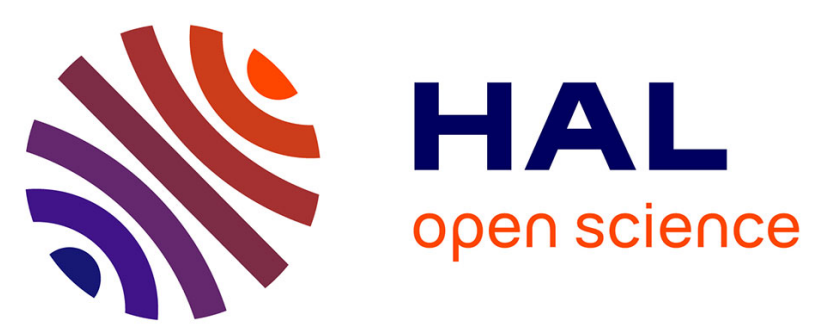

\title{
A fine-scale analysis reveals microgeographic hotspots maximizing infection rate between a parasite and its fish host
}

Eglantine Mathieu-Bégné, Simon Blanchet, Olivier REY, Orlane Scelsi, Camille Poesy, Geoffrey Marselli, Géraldine Loot

\section{To cite this version:}

Eglantine Mathieu-Bégné, Simon Blanchet, Olivier REY, Orlane Scelsi, Camille Poesy, et al.. A finescale analysis reveals microgeographic hotspots maximizing infection rate between a parasite and its fish host. Functional Ecology, 2022, 36 (2), pp.380-391. 10.1111/1365-2435.13967 . hal-03455005

\section{HAL Id: hal-03455005 https://hal.science/hal-03455005}

Submitted on 29 Nov 2021

HAL is a multi-disciplinary open access archive for the deposit and dissemination of scientific research documents, whether they are published or not. The documents may come from teaching and research institutions in France or abroad, or from public or private research centers.
L'archive ouverte pluridisciplinaire HAL, est destinée au dépôt et à la diffusion de documents scientifiques de niveau recherche, publiés ou non, émanant des établissements d'enseignement et de recherche français ou étrangers, des laboratoires publics ou privés. 


\title{
A fine- scale analysis reveals microgeographic hotspots maximizing infection rate between a parasite and its fish host
}

\section{Eglantine Mathieu- Bégné ${ }^{1,2,3}$ Simon Blanchet ${ }^{1,2}$ Olivier Rey ${ }^{3}$ Orlane Scelsi ${ }^{1}$ Camille Poesy $^{2}$ Geoffrey Marselli ${ }^{2}$ Géraldine Loot ${ }^{1,4}$}

\author{
${ }^{1}$ Evolution et Diversité Biologique, Université Paul Sabatier (UPS), Centre National de la Recherche Scientifique, \\ Ecole Nationale pour la Formation Agronomique (ENFA), UMR5174 EDB, Toulouse, France \\ ${ }^{2}$ Station d'Ecologie Théorique et Expérimentale, CNRS, UPS, UMR5321 SETE, Moulis, France \\ ${ }^{3}$ Interactions Hôtes- Pathogènes- Environnements, Univ. Montpellier, CNRS, Ifremer, Univ. Perpignan Via Domitia, \\ UMR5244 IHPE, Perpignan, France \\ ${ }^{4}$ Institut Universitaire de France, Paris, France
}

\section{Correspondence}

Eglantine Mathieu-Bégné_Email: eglantine.mb@gmail.com

\section{Funding information}

This work was supported by the Agence Nationale de la Recherche (project INCLIMPAR, grant no. ANR- 11- JSV70010), BiodivERsA (project PROBIS) and the Institut Universitaire de France. E.M.- B. was financed by a PhD grant from the French Ministry for Education and Sciences. This work was carried out within the framework of the 'Laboratoire d'Excellence' (LABEX) TULIP (ANR- 10- LABX- 41).

\section{Abstract}

For parasites, finding their hosts in vast and heterogeneous environments is a task that can be complex. Some parasite species rely on elaborate strategies to increase encounter rate with their hosts (e.g. behavioural modification of host), but others do not. For these parasites, a key issue is to reveal the processes that enable them to successfully find their hosts and complete their life cycles.

Here, we tested the hypothesis that infective larvae of the freshwater ectoparasite Tracheliastes polycolpus are not homogeneously distributed along the river and preferentially occur in very specific microhabitats that maximize encounter rate, and hence infection rate, with their host fish. To do this, we combined an in situ experiment (caging) with an empirical survey carried out on the same sites to identify potential 'hotspots' of infection at the microgeographic scale and their environmental characteristics.

Experimental and empirical results demonstrated that infections were not evenly distributed among microhabitats, and that infections were spatially aggregated in hotspots at a very fine spatial grain.

We further found that certain combinations of environmental variables were consistently and nonlinearly associated with higher infection rate for both caged and wild- caught fish. Microhabitats characterized by very low or high stream velocities, associated with medium or very small substrate, respectively, and a deep water column were strongly and repeatedly associated with higher infection rates. These microhabitats could concentrate parasites and/or promote physical contact with the hosts.

We conclude that the characteristics of some microhabitats could facilitate contact between hosts and parasites and explain how some parasites manage to find their hosts in complex environments.

\section{Keywords}

aggregation, encounter filter, freshwater, host- parasite interactions, microhabitat 


\section{1- INTRODUCTION}

Parasites strongly rely on host- related factors to successfully complete their life cycles (Hall \& Ebert, 2012; Wolinska \& King, 2009). Once they have found their target host, they still have to overcome host defences to interact sustainably and reproduce (Combes, 2001). Combes (2001) conceptualized the success of parasites in two main stages. The first stage refers to the spatial and temporal overlap between parasites and potential hosts that is necessary for the parasites to find their future hosts, the so-called 'encounter filter' (Combes, 2001). The second stage, 'compatibility filter', occurs when the parasites have encountered their hosts and refers to the conditions required for the parasites to exploit their hosts on a long- term basis, with presumably negative effects on the hosts (Combes, 2001). Since parasites can have drastic impacts on their hosts and on the overall ecosystem via cascading effects, understanding the factors that influence a parasite's ability to successfully complete its life cycle is a critical issue (Hoberg et al., 2015; Morand \& Deter, 2007).

Compared to studies focusing on the compatibility filter, very few studies have focused on the factors involved in the encounter filter, despite this being the first step in a successful infection (Kuris et al., 2007; Lacey et al., 2014; Ward et al., 1998). For an infective larva, encountering a new host - or for a parasite with a complex life cycle, switching from one host species to another species - is like finding a needle in a haystack because (a) parasites are small, (b) hosts are rare, (c) host are dynamic in space and time, and (d) the environment is immense. An intriguing issue for ecologists and evolutionary biologists is to reveal how parasites meet their hosts in open environments to complete their life cycles. Several parasite strategies aiming at increasing encounter rate have been documented. These strategies encompass the use of environmental or host cues, behavioural modification of their hosts and temporal synchronicity with their hosts. The use of host or environmental cues allows parasites to actively track their hosts (e.g. Lacey et al., 2014; Lawrence, 1981; Pasternak, 2004). For instance, the parasitic barnacle Heterosaccus dollfusi uses chemical cues to find its crab host (Pasternak, 2004). Likewise, numerous studies have shown that certain parasites are able to modify the behaviour of their host, which favours parasite transmission (Hughes et al., 2012). This type of host behavioural manipulation is often documented for parasites with complex life cycles requiring trophic transmission from one host species to another (e.g. Adamo, 2002; da Silva \& Langoni, 2009; Mikheev et al., 2015). Alternatively, certain parasites have been shown to synchronize their circadian shedding rhythms with the circadian activities of their hosts such that the peak of infective larvae released into the environment is maximal when hosts are most abundant (e.g. Gautret et al., 1995; Theron \& Combes, 1995). Finally, high fecundity is an adaptive trait widely observed in parasites, which passively increases the encountering probability between parasite infective stages and hosts (Poulin, 1995a, 1995b; Rea \& Irwin, 1994).

Surprisingly, some parasite species do not seem to present specific strategies to promote their encounter rate, and therefore to maintain their life cycles. In these cases, environmental factors might facilitate the process of infection. If the infective stages of the parasite are distributed randomly in the environment, the encounter rate should be very low if hosts are also diluted in the environment. Alternatively, if the infective stages of the parasite are not distributed randomly in the environment, but rather aggregated in some specific microhabitats, the encounter rate should be higher if hosts also use (at least occasionally) the same specific microhabitats (spatial matching, Benavides et al., 2012; Paull et al., 2012). In this case, infections should occur specifically at some microgeographic 'hotspots', which can be seen as a strategy for parasites to optimize the rate of infection (Zimmermann et al., 2016). Some microhabitats could indeed offer particularly favourable conditions for the completion of the life cycles of parasites, for instance by locally concentrating the number of infective stages (Browman et al., 2004; Cardon et al., 2011; Marcogliese, 2016). If these hotspots of infection exist, it means that the probability that a host is infected is not homogeneous at the microgeographic scale. Also, if hosts are relatively sedentary, the spatial distribution of parasitized hosts might itself be heterogeneous and might overlap with the distribution of infection hotspots.

So far, studies have investigated the existence of infection hotspots at large to moderate spatial scales such as hundreds to thousands of metres (e.g. Bousema et al., 2010; Murphy et al., 2012; Poulin \& FitzGerald, 1989; Ramirez- Sierra et al., 2010; Thamm et al., 2009). However, very few studies have tested whether infection rate could be driven by environmental factors at the microgeographic scale (but see Zimmermann et al., 2016 for a study considering $10 \mathrm{~m}$ long microhabitats, and Williams \& Esch, 1991 for a pioneer microgeographic scaled study on parasite prevalence). We argue that studies at a very fine spatial scale could improve our understanding of the 
factors favouring the encounter between infective parasite larvae and hosts, even for parasites not displaying active strategies to increase encounter rate. These very small- scale studies are also crucial to better predict potential infection hotspots, which are key targets for slowing the life cycles of parasites and thus eradicating pathogenic parasites to humans and/or wild animals.

Here, we aimed to investigate the existence of microgeographic hotspots of parasite infections associated with environmental feature at a very fine scale. First, we tested whether the probability of being infected was distributed heterogeneously $-r$ ather than randomly- among microhabitats, which would suggest the existence of infection hotspots. Second, we tested whether potential infection hotspots resulted in aggregation of parasitized hosts at a fine spatial scale. Finally, we tested whether specific environmental factors were associated with potential infection hotspots. We focused on an ectoparasite, the crustacean Tracheliastes polycolpus, with a direct life cycle and infecting several freshwater fish species (Loot et al., 2004; Lootvoet et al., 2013). This parasite does not use chemical cues or host behavioural modifications to increase its encountering rate (as most fish ectoparasites, but see Mikheev, 2011). Parasitic females lay a relatively low number of eggs (usually less than a hundred, Loot et al., 2011) that give birth to free- living infective larvae. Moreover, infective larvae exhibit relatively poor locomotory abilities preventing larvae from an efficient active search of the host (Fryer, 1982), and display short life span (a few days, Mazé- Guilmo, 2016). This parasite species infects host fish species occasionally inhabiting large rivers whose water flow can be relatively high (up 50-100 $\mathrm{m}^{3} / \mathrm{s}$, Mathieu- Bégné, Blanchet, et al., 2021), which suggests that if infective larvae are distributed randomly in space, the concentration of infective stages per litre should be extremely low. Despite these biological features, $T$. polycolpus can infect a relatively rare host species, Leuciscus sp. (generally 0.02 to 0.12 individuals per $\mathrm{m}^{2}$ of rivers in favourable areas), which is its main host species in southwestern France. Some dace individuals harbour sometimes up to 80 parasites (Loot et al., 2004; Lootvoet et al., 2013). Tracheliastes polycolpus is also able to infect alternative host species such as the gudgeon Gobio occitaniae and the minnow Phoxinus phoxinus that are more abundant than dace, but less parasitized (Lootvoet et al., 2013). This system hence constitutes an ideal opportunity to test our predictions.

We first performed an in situ caging experiment to test for a non- random distribution of infections among contrasted yet geographically close microhabitats, separated by a few metres, which would suggest aggregation in hotspots of infection. In this experiment, we used F1 hosts from a common pool of breeders to control for potential confounding effects associated with host- related factors linked to the compatibility of hosts and parasites, such a prerequisite rarely being considered. Second, through an exhaustive sampling at a very fine spatial scale, we tested whether wild parasitized hosts from the same river were also spatially aggregated into hotspots. Finally, we compared microhabitat characteristics predicting the distribution of infected hosts in our caging and empirical approaches. We predict that infections in experimental hosts will be aggregated in cages located in specific microhabitats (hotspots of infection). If so, and if wild parasitized hosts are poorly mobile, we expect similar patterns of spatial aggregation for wild parasitized hosts. In contrast, if hosts are highly mobile, parasitized hosts should spread into the landscape, and in that case no clear pattern of spatial aggregation of parasitized hosts should emerge. Finally, we expect that the same environmental factors will explain differences in infection rate among microhabitats measured in the caging and empirical approaches.

\section{2- MATERIALS AND METHODS}

\section{2-1 In situ caging experiment: Testing for spatial aggregation in infection}

We first designed a semi- natural experiment by placing cages in pre- determined microhabitats to test whether infections were randomly distributed, or on the contrary aggregated in some cages. An aggregation pattern would indicate the presence of hotspots of infection. In this experiment, we focused on infection occurring between $T$. polycolpus and its main host, the rostrum dace Leuciscus burdigalensis (Lootvoet et al., 2013). From August to September 2017, we settled 16 cages along a stretch of the Arize River (southwestern France, Mas d'Azil, $X=$ $366,422, Y=4,770,813$, WGS 84/UTM zone 31N). Each cage was made of PVC tubes, $25 \mathrm{~mm}$ in diameter, assembled in the form of a rectangular cube of $30 \times 50 \times 80 \mathrm{~cm}$ and covered with a plastic mesh of $1 \mathrm{~cm}$. Each cage was anchored to the bedrock in various microhabitats along a river stretch of about $200 \mathrm{~m}$ long (Figure 1a). We selected microhabitats based on the visual inspection of stream velocity, depth and distance from the bank. We distributed the cages in the main microhabitats available along the river stretch. As the infective stage of $T$. 
polycolpus is tiny and has a poor swimming ability, we suspected that habitats with low stream velocity will be better for infections, and we hence contrasted these habitat types to microhabitats with higher stream velocity. Each cage contained two rostrum dace L. burdigalensis. Dace were standardized according to their genetic background, age, body size and weight to control for potential confounding host- related factors. We specifically used F1 dace that were bred at the U3E experimental platform (INRAe, Rennes, France Unité Expérimentale d'Ecologie et d'Ecotoxicologie Aquatique) from wild progenitors caught in the Oir River (Ille- et- Villaine; France). We selected individuals of the same age (i.e. 3 years old) and with similar body size and weight (body size: 163 $\mathrm{mm}$ on average, ranging from 155 to $213 \mathrm{~mm}$; body weight: $45 \mathrm{~g}$ on average, ranging from 44 to $46 \mathrm{~g}$ ). All the fish used in this experiment were naïve about previous exposure to $T$. polycolpus, although the genitors used for generating offspring were exposed to the parasite in the wild before being brought to the facility. The caging experiment lasted 45 days during which fish were visually checked and cages were cleaned every 2 days. After 45 days, fish were removed from the cages, they were euthanatized using an overdose of benzocaine according to French legislation and the number of parasites carried by each fish was recorded. The experiment was performed in agreement with the national legislation (Arrêté Préfectoral 23 May 2017 and 22 May 2018) and did not require ethical approval.

\section{2-2 Empirical survey: Testing for spatial aggregation of parasitized hosts in wild populations}

We conducted an electrofishing sampling on the same site as the caging experiment (Mas d'Azil in the Arize River). We replicated the sampling during July 2017 (i.e. before the setting of the cages) and July 2018 (i.e. after the setting of the cages). Sampling was achieved following a downstream- upstream direction in 80 microhabitats in 2017 (Figure 2a) and 82 microhabitats in 2018 (Figure 2b) to cover a river section of nearly $200 \mathrm{~m}$. We exhaustively sampled potential hosts by immerging the anode for a few seconds in each microhabitat and catching all visible fish with a hand- net. Each microhabitat was separated by $3 \mathrm{~m}$ to limit perturbation (Copp \& Garner, 1995). We specifically focused on the potential and most abundant secondary hosts of $T$. polycolpus; the Occitan gudgeon Gobio occitaniae, and the European minnow Phoxinus phoxinus (Lootvoet et al., 2013). We did not focus on $L$. burdigalensis for this approach because they were not abundant enough to be considered in the analyses. Gudgeons and minnows are small- bodied fish measuring $<15 \mathrm{~cm}$ in length and feeding on invertebrates. Gudgeons are mainly feeding on the bottom, whereas minnows are mainly found in the water column feeding on drifting invertebrates. We can therefore surmise that gudgeons are less mobile than minnows (Keith et al., 2011), and hence that parasitized gudgeons will display the patterns of spatial aggregation similar than those found for caged dace, which might not be the case for minnows. All individuals from a microhabitat were kept isolated in an individual bucket supplied with air. Fish were then anesthetized, measured and parasites were counted before releasing fish back to the river.

\section{2-3 Abiotic characterization of microhabitats}

Microhabitat was defined by an area of $\sim 1 \mathrm{~m}^{2}$ matching either the area where a cage was settled or where the anode was immersed during the electrofishing session. Microhabitats were characterized by measuring the core geographic coordinates (WGS 84/UTM zone 31N, measured using the GPS Garmin ${ }^{\circ}$ eTrex 10), the water column depth $(\mathrm{cm})$, the stream velocity $\left(\mathrm{m} / \mathrm{s}\right.$, measured $7 \mathrm{~cm}$ above substrate level using the $0 T^{\circ} \mathrm{Z} 400$ counter associated with the current metre $\mathrm{OTT}^{\circ} \mathrm{C} 2$ ) and the substrate composition in a 1- $\mathrm{m}$ circle around the cage or electrofishing point. The percentage of each substrate categories was defined according to substrate size: $<2 \mathrm{~cm}, 2-10 \mathrm{~cm}, 10-$ $20 \mathrm{~cm}$ and over $20 \mathrm{~cm}$. Substrate categories were then summarized in two synthetic variables using a principal component analysis (PCA) to avoid over- parametrization and collinearity among variables in subsequent models. We kept the two first components as synthetic variables as they summarized $83 \%$ of the total variance. The first component, synthesizing $50 \%$ of the total variance, distinguished the substrate composed of a small size substrate $(2-10 \mathrm{~cm})$ from a large size substrate $(>20 \mathrm{~cm})$. The second component, synthesizing $33 \%$ of the total variance, distinguished a smallest size substrate $(0-2 \mathrm{~cm})$ from a medium size substrate $(10-20 \mathrm{~cm})$. We named these synthetic variables 'granulometry 1 ' and 'granulometry 2 ' respectively (Figure S1).

\section{2-4 Statistical analyses}

2.4.1 Assessment of the spatial distribution of infected hosts 
We first tested whether infections were randomly distributed among cages or not. We excluded from this analysis two cages - in which one of the two fish died - to control for host density. We then computed the variance to the mean ratio which is a measure of parasite aggregation and calculated here as the variance to the mean ratio of $T$. polycolpus number per cage (Poulin, 1993). If parasites are randomly distributed among cages, the variance to the mean ratio is expected to be close to 1 . On the contrary, if parasites are aggregated in a few cages (i.e. hotspots of infection), the variance to the mean ratio is supposed to be greater than 1 (Poulin, 1993). We further simulated the expected variance to the mean ratio in the case of a random distribution of $T$. polycolpus: in such a case one would expect the number of parasites to follow a Poisson distribution with a mean matching the mean observed in our dataset (i.e. mean $_{\mathrm{obs}}=1.929$ parasites per cage). We finally compared the observed variance to the mean ratio to the distribution of 10,000 simulated variance to the mean ratios. This test assumes that aggregation is due to the microhabitat in which the cages have been settled and not to host- related factors. Although hosts were genetically and phenotypically homogeneous among cages, we further tested whether $T$. polycolpus distribution among cages was aggregated, while accounting for potential and unmeasured host effects. To do so, we simulated the variance to the mean ratio by reshuffling the identity of cages while keeping constant the number of parasites observed on each host. We compared the observed variance to the mean ratio to the distribution of variance to the mean ratios after 10,000 simulations.

Second, we tested whether parasitized hosts were spatially aggregated or homogeneously distributed at the microgeographic scale in wild host populations. We conducted a join count analysis correlating the parasite occurrence (binary variable: 1 corresponds to the presence of at least one parasite in hosts caught in a given microhabitat, 0 corresponds to the absence of parasite in hosts caught in a given microhabitat) with geographical coordinates using the function joincount. $m c$ from the R package spdep (Bivand et al., 2005). This analysis is based on a theoretical distribution of the object of interest, here parasitized hosts, in a grid of cells. We defined a grid of $20 \times 10$ cells, so that a cell matches a microhabitat of $1 \mathrm{~m}^{2}$, defined by actual geographical coordinates. This analysis aims to test whether parasite occurrences are aggregated (i.e. occur in neighbouring cells) compared to a null expectation where occurrences are randomly distributed in the grid (Lawson, 2010). Neighbour relationships between cells were defined by queen movements (i.e. vertically, horizontally and diagonally). Significance was assessed from 999 random permutations, separately for the sampling carried out in 2017 and for the sampling carried out in 2018.

\subsubsection{Relationships between environmental factors and infection rate}

We first tested whether the environmental features of microhabitats were significantly linked to parasite load observed for each caged individual. We built a GLM linking parasite load to microhabitat environmental features (i.e. depth, stream velocity, granulometry 1 and granulometry 2 ) as well as interactions between stream velocity and depth and between stream velocity and granulometry 1 and granulometry 2 respectively. We focused on these specific interaction terms because synergetic effects between stream velocity and depth are expected to favour parasite development (e.g. both calm and deep environment, Loot et al., 2004). Moreover, stream velocity can influence the movement of particles according to their size (Hjulstrom, 1935) and consequently T. polycolpus larvae dispersion. We further included a quadratic term for stream velocity and depth as visual inspections of the data indicated a potential nonlinear relationship between parasite infection and stream velocity and between parasite infection and water column depth respectively. Quadratic terms were not added to other variables to avoid over- parameterizing the models. For this analysis, all cages were considered, and we therefore included the number of surviving fish, two or one, per cage as a covariate. A Poisson error term was assumed for this model. We did not include a random effect on cage identity since the variance estimated for this random effect was null (and thus negligible, Pasch et al., 2013). Similarly, we did not take into account spatial autocorrelation since we did not detect significant spatial autocorrelation in the model residuals (Moran test, $p$ - value $=0.655$, Dormann et al., 2007). From this full model, all possible models were built and tested. We conducted a model selection approach based on the Akaike information criterion (AIC) using the function dredge from the R package MuMin (Barton, 2015). Specifically, each model was sorted in an increasing order according to their AIC, and the difference in AIC between each model and the model with the lowest AIC value ( $\triangle \mathrm{AIC}$ ) was computed. The models with a $\triangle \mathrm{AIC}<2$ were considered as the most likely to be supported by the data, and were considered as the 'best models' 
(Bozdogan, 1987). Finally, variable importance was computed as their percentage of occurrence across the set of best models.

We then tested whether the environmental features of microhabitats were linked to the parasite prevalence in wild host populations. We built a generalized linear mixed model linking parasite prevalence (i.e. the number of parasitized fish over the total number of fish sampled in a microhabitat) to microhabitat environmental features (i.e. depth, stream velocity, granulometry 1 , granulometry 2 as well as interactions between stream velocity and depth and between stream velocity and granulometry 1 and granulometry 2 respectively). As in the model described above, we included the quadratic term associated with stream velocity and water column depth. We assumed a binomial error term in this model. We included both the year of sampling (2017 or 2018) and the fish species (gudgeon or minnow) as random terms. We did not detect spatial autocorrelation in model residuals (Moran test, $p$ - value $=0.865$ ) and hence did not include terms related to spatial autocorrelation. The same model selection approach as described above was applied starting from the full model. All statistics were run using $R$ software (version 4.0.0, R Core Team, 2020).

\section{3- RESULTS}

\section{3-1 Spatial distribution of infected hosts in cages}

In the caging experiment, we observed a variance to the mean ratio of 7.5 , which indicates a clear pattern of spatial aggregation of infections by $T$. polycolpus. In other words, the probability of being infected by $T$. polycolpus was not homogeneous among cages (microhabitats), which resulted in a few cages with a high number of parasites on hosts (up to 14 parasites per cage), whereas in a half of the cages all fish remained uninfected (Figure 1b). We found that the variance to the mean ratio we observed was significantly different from variance to the means ratios computed from a random distribution and irrespectively from host- related factors ( $p$-value $<0.001$, Figure S2a). Similarly, we found that the observed variance to the mean ratio significantly differed from the variance to the mean ratio computed from a random distribution that considered host- related factors ( $p$-value $=0.002$, Figure $\mathrm{S} 2 \mathrm{~b})$.

\section{3-2 Spatial distribution of infected hosts in natural environments}

Overall, 977 fish (54 gudgeons and 923 minnows) were sampled in 2017 including 52 parasitized fish (14 gudgeons and 38 minnows, total prevalence $=5 \%$ ) and 262 fish (78 gudgeons and 184 minnows) were sampled in 2018 including 27 parasitized fish (19 gudgeons and 8 minnows, total prevalence $=10 \%$ ). The joint count analysis revealed a significant spatial aggregation of parasitized hosts in 2017 (statistic $=12$, rank of the observed statistic $=1000, p$ - value $=0.001$, see Figure $2 \mathrm{c}$ ) and in 2018 (statistic $=13$, rank of the observed statistic $=1000, p$ - value $=$ 0.001 , see Figure $2 \mathrm{~d}$ ). Hence, we detected microgeographic hotspots in which parasitized hosts occurred more frequently than expected by chance along 2 consecutive years. Interestingly, the position of these hotspots was strongly consistent spatially in 2017 and 2018, with hotspots located near the upstream weir and in the downstream area of the sampled stream section (Figure 2c,d). These hotspots of infection found for wild (freeswimming) hosts were also strongly consistent microgeographically to those identified for caged hosts (see Figures 1 and 2).

\section{3-3 Relationships between environmental factors and infection rate}

For the caging experiment, the model selection approach identified six models that were supported by the data with a similar likelihood ( $\triangle \mathrm{AIC}<2$, Table 1). Five out of these six models (referred hereafter as best models) retained as explicative variables stream velocity, granulometry 2 and the interaction term between stream velocity and granulometry 2 (importance $=90 \%$, Table 1 ; Figure S3), and four out of these best models consistently retained water depth and the quadratic terms of stream velocity (importance $>70 \%$, Table 1; Figure S3). This indicated that higher parasite loads are predicted in microhabitats characterized by low stream velocity $(0-0.10 \mathrm{~m} / \mathrm{s}$, Figure 3a) and medium size substrate on the one side $(10-20 \mathrm{~cm}$, Figure S1), and in microhabitats characterized by high stream velocity $(0.40-0.60 \mathrm{~m} / \mathrm{s}$, Figure $3 \mathrm{a})$ and substrate composed of small size substrate $(0-2 \mathrm{~cm}$, Figure S1) on the other side (Figure S1; Figure 3a). Similarly, higher parasite loads are predicted for microhabitats characterized by a deep water column (60-80 cm, Figure $3 b)$. 
In the empirical approach, the model selection procedure identified eight models that were supported by the data with a similar likelihood ( $\triangle \mathrm{AIC}<2$, Table 2 ). The eight best models consistently retained the quadratic term of stream velocity as an explicative variable (importance $=100 \%$ ), and to a lesser extent water depth (importance $=$ $50 \%$, Figure S4; Table 2). According to these two most influential variables, prevalence was predicted to be higher for microhabitats characterized by both slow and high stream velocity (compared to microhabitats with a moderate stream velocity, that is between $0-0.10$ and $0.40 \mathrm{~m} / \mathrm{s}$, Figure 4 ) and to lesser extent for microhabitats characterized by a deep water column (Table 2).

\section{4- DISCUSSION}

In a semi-natural experiment controlling for hosts' movements and their intrinsic characteristics, we demonstrated that infection by $T$. polycolpus did not occur randomly at the microgeographic scale, highlighting the existence of hotspots of infection at a very fine spatial extent. In this experiment, host fish were maintained in cages that were separated by a few metres one from the others, and despite this proximity, we revealed strong variance in infection rate among cages. We used naïve hosts that were standardized for individual characteristics that are likely to impact host susceptibility to parasitism such as body size, weight, age and the genetic background (Blanchet, Méjean, et al., 2009; Blanchet, Rey, et al., 2009; Sutherland et al., 2011). Host factors hence unlikely explained the variance in infection rates. Furthermore, even when we statistically accounted for potential host variability, we still demonstrated that parasite infections were high in a few cages and low to null in most other cages. Such heterogeneity in infection among cages suggests that variability in exposure through space led to this spatially aggregated pattern. It is worth noting that spatial aggregation could also result from the variability associated with spatial variance in parasite virulence (Combes, 2001). However, we conducted our experiment in a single locality in which the parasite population was shown to be genetically homogeneous, and thus in which parasites should display the same level of virulence (Mazé- Guilmo, 2016). Moreover, and as stated above, some cages separated by only a few metres strongly varied in terms of infection rate, diminishing the potential influence of spatial variance in parasite virulence. We consequently concluded that the microgeographic aggregation of parasites that we observed most likely results from heterogeneity in parasite exposure through space.

In the caging experiment, hosts were not allowed to move freely, and we could expect that movements of fish among microhabitats would blur these heterogeneous distributions in infection rates. We hence ran an empirical survey investigating how the infection rate varies in the riverscape at a very fine spatial scale and using wild and free- swimming hosts. This approach also revealed strong and significant aggregations of parasitized hosts in specific microhabitats. This finding was extremely robust, since this pattern was repeatable over 2 subsequent years, but also among the host species. This suggests a strong consistency in the microhabitats that are favourable for the parasite. Specifically, parasitized hosts identified in the empirical survey tended to aggregate in microhabitats that we previously identified as hotspots of infection in the caging experiment (Figure 1a and 2a,b). Contrary to our expectation that minnows were supposed to be more mobile, we found that both parasitized gudgeons and minnows tended to stay in these hotpots of infection. Hence, parasitized hosts may stay in infection hotspots either because the host species we considered are actually highly sedentary and/or because host movement is - negatively - affected by parasites (Binning et al., 2017; Fellous et al., 2011; van Dijk et al., 2015). This later hypothesis is particularly meaningful for a parasite like T. polycolpus that damages host fins and directly alters host movements (Blanchet, Méjean, et al., 2009; Loot et al., 2004). We hence suggest that encounter rate between parasites and hosts may be favoured in some specific microgeographic areas of a complex landscape, since our study focused on a stretch of rivers as short as $200 \mathrm{~m}$ long. A few other studies suggested similar results, notably showing that hosts are able to develop behavioural resistance to parasites based on habitat choice in order to avoid certain areas in which encounter rate is high (Decaestecker et al., 2002; Karvonen et al., 2004). However, studies focusing on the role of the local context on infection rate, so far, did not provide evidence for hotspots of infection at such a small spatial scale (Borer et al., 2010; Jennett et al., 2013; Poulin \& FitzGerald, 1989; Thamm et al., 2009). Host habitat, and more precisely microhabitat occupancy, is thus a key component of encounter rate and hence infection rate.

Microhabitats sustaining high infection rates were characterized by specific environmental features that were congruent across the two approaches. Infection rate was consistently linked to stream velocity (sometime in 
interaction with substrate size such as in the caging experiment) with microhabitats characterized by moderate stream velocity ( 0.10 to $0.40 \mathrm{~m} / \mathrm{s}$ ) harbouring less parasitized fish than those associated with high or low stream velocity. We also found that a deep water column generally favoured infection rate. Granulometry (fine- sized sediments on one side and medium- sized sediments on the other side) was also found to be significantly associated with parasite transmission at the local scale. However, since the effect of substrate composition was detected only in the caging experiment, and because substrate sizes often covary with water flow in rivers, the role of substrate on parasite transmission would need further validations to discriminate between an actual biological effect or a spurious association due to covariation between water flow and granulometry. Importantly, there was a strong congruency in the environmental features (at least for stream velocity) favouring infections since they were consistent across host species (between the caging experiment and the empirical approach) but also highly repeatable over time (within the empirical approach), which demonstrates the robustness of our findings. These environmental features may favour encounter rate between $T$. polycolpus and its hosts either by increasing the density of infective stages (e.g. because these environmental conditions trigger larval hatch or/and favour their survival) or by increasing the contact rate between hosts and parasites. Our experimental design does not allow distinguishing one of these two- non- mutually exclusive- hypotheses, and an interesting research avenue would be to quantify the local density of infective larvae using environmental DNA approaches at a very fine spatial scale. Nonetheless, we can speculate that habitats displaying low stream velocity $(0-0.10 \mathrm{~m} / \mathrm{s})$ and associated with medium substrate (i.e. $10-20 \mathrm{~cm}$ ) could favour the accumulation of poorly mobile infective larvae (Loot et al., 2004). Here we measured stream velocity near the substrate and the highest stream velocity (0.40$0.60 \mathrm{~m} / \mathrm{s}$ ) was associated with the smallest substrate particles $(0-2 \mathrm{~cm})$ in microhabitats favouring parasite infections. Consequently, we can also suspect that the highest stream velocity $(0.40-0.60 \mathrm{~m} / \mathrm{s})$ may favour contact rate by suspending the infective larvae into the water column rather than just drifting them away. Such microhabitats probably correspond to whirlpool areas that suspend infective larvae in the water column. Contact rate with potential hosts could thus be increased through a 'washing machine' effect. Hence both low and high stream velocity areas could constitute favourable microhabitats for $T$. polycolpus infection. Nonetheless, this finding holds true only for the ranges of stream velocity investigated in this stream section. It is likely that the conclusion about the effect of stream velocity on infection rate could change if a wider range of velocity would have been investigated (for instance if stream velocity higher than $2 \mathrm{~m} / \mathrm{s}$ would have been investigated). Finally, our findings also suggest that a deep water column may participate to increase locally the density of $T$. polycolpus infective larvae (see Loot et al., 2004). Our results echo other studies having suggested that - for instance- in sea lice infecting salmonid hosts, stream velocity of $\sim 0.17 \mathrm{~m} / \mathrm{s}$ was high enough to increase contact rate between hosts and parasites, but also low enough to ease the anchoring process for the infective larvae (Samsing et al., 2015). Our results also complement studies conducted in controlled conditions that have shown that low water flow can also favour parasite accumulation (Bjork \& Bartholomew, 2009; Hallett \& Bartholomew, 2008). However, further experimental studies are still needed to understand how these microhabitats favour host- parasite interactions. Irrespectively of the underlying mechanisms, our findings suggest that this is not one singular feature that mediates the infection rate of a parasite, but rather a particular combination of environmental features that lead to hotspots of infections. More generally these results indicate that the abiotic environment influences infection rate much more than previously thought, hence complicating the triple interaction between hosts, parasites and the abiotic environment.

To conclude, we demonstrated that hotspots of infection (i.e. areas in which infection rate is substantially higher than elsewhere) exist at the microgeographic scale, which lead to a highly heterogeneous distribution of infected hosts in the landscape. These hotspots of infection were predicted by specific environmental features that likely favour the encounter rate between hosts and parasites and/ or local density of infective larvae. Overall, infection rate was much higher in these specific areas, and once parasitized the hosts seem to remain in these (or close to these) areas. We argue that, for parasites that do not exhibit evident evolutionary strategies to increase encounter rate, the occupancy of specific microhabitats might be a general mechanism explaining how encounter rate between host and parasites can be favoured in vast and open environments such as rivers, in other words how a parasite can find its needle in this haystack. 


\section{COMPETING INTERESTS}

The authors declare having no competing interests.

\section{ACKNOWLEDGEMENTS}

The authors thank all the people who invested their time in this project and made it possible. They are very grateful to Yoann Buoro, Maxim Lefort, Allan Raffard and Lucie Di Gesu who contributed to the fieldwork, experiment setting and data collection. They also thank Thierry Paulin who kindly allowed us to conduct our caging experiment on his property and Antoine Gallard for having provided the dace along with advice to take good care of them. Finally, they thank the two anonymous reviewers who helped them to substantially improve the present manuscript.

\section{AUTHORS' CONTRIBUTIONS}

G.L., O.R. and S.B. developed the original idea; E.M.- B., G.L., O.R. and S.B. supervised and coordinated the study; E.M.- B., S.B., O.R., O.S., C.P., G.M. and G.L. conducted the experiments and acquired the data; E.M.- B. and O.S. ran the statistical analyses; E.M.- B., S.B., O.R. and G.L. wrote the manuscript. All authors approved the final version of the manuscript, and all agreed to be held accountable for the content therein.

\section{DATA AVAILABILITY STATEMENT}

Data associated with this study along with $\mathrm{R}$ code used have been submitted on the Figshare repository available at https:// doi.org/10.6084/m9.figsh are.14473467 (Mathieu- Bégné, Loot, et al., 2021).

\section{ORCID}

Eglantine Mathieu- Bégné https://orcid.org/0000-0002-6846-5491

Simon Blanchet https://orcid.org/0000-0002-3843-589X

Olivier Rey https://orcid.org/0000-0003-3699-7204 


\section{REFERENCES}

Adamo, S. A. (2002). Modulating the modulators: Parasites, neuromodulators, and host behavioral change. Brain, Behavior and Evolution, 60(6), 370-377. https://doi.org/10.1159/00006 7790

Barton, K. (2015). MuMIn: Model selection and model averaging based on information criteria (AlCc and alike). https://cran.r- proje ct.org/web/ packag es/MuMIn/ index.html

Benavides, J., Walsh, P. D., Meyers, L. A., Raymond, M., \& Caillaud, D. (2012). Transmission of infectious diseases en route to habitat hotspots. PLoS One, 7(2), e31290. https://doi.org/10.1371/journ al.pone.0031290

Binning, S. A., Shaw, A. K., \& Roche, D. G. (2017). Parasites and host performance: Incorporating infection into our understanding of animal movement. Integrative and Comparative Biology, 57(2), 267- 280. https://doi.org/10.1093/icb/icx024

Bivand, R., Bernat, A., Carvalho, M., Chun, Y., Dormann, C., Dray, S., Halbersma, R., Lewin- Koh, N., Ma, J., \& Millo, G. (2005). The spdep package. Comprehensive R Archive Network, Version 05-83.

Bjork, S. J., \& Bartholomew, J. L. (2009). The effects of water velocity on the Ceratomyxa shasta infectious cycle. Journal of Fish Diseases, 32(2), 131- 142. https://doi.org/10.1111/j.1365- 2761.2008.00964.x

Blanchet, S., Méjean, L., Bourque, J.- F., Lek, S., Thomas, F., Marcogliese, D. J., Dodson, J. J., \& Loot, G. (2009). Why do parasitized hosts look different? Resolving the 'chicken- egg' dilemma. Oecologia, 160(1), 37- 47. https://doi.org/10.1007/s0044 2-008-1272- y

Blanchet, S., Rey, O., Berthier, P., Lek, S., \& Loot, G. (2009). Evidence of parasite- mediated disruptive selection on genetic diversity in a wild fish population. Molecular Ecology, 18(6), 1112- 1123. https:// doi.org/10.1111/j.1365-294X.2009.04099.x

Borer, E. T., Seabloom, E. W., Mitchell, C. E., \& Power, A. G. (2010). Local context drives infection of grasses by vector- borne generalist viruses: Local vs. regional context and infection risk. Ecology Letters, 13(7), 810818. https://doi.org/10.1111/j.1461- 0248.2010.01475.x

Bousema, T., Drakeley, C., Gesase, S., Hashim, R., Magesa, S., Mosha, F., Otieno, S., Carneiro, I., Cox, J., Msuya, E., Kleinschmidt, I., Maxwell, C., Greenwood, B., Riley, E., Sauerwein, R., Chandramohan, D., \& Gosling, R. (2010). Identification of hot spots of malaria transmission for targeted malaria control. Journal of Infectious Diseases, 201(11), 1764-1774. https://doi.org/10.1086/652456

Bozdogan, H. (1987). Model selection and Akaike's information criterion (AIC): The general theory and its analytical extensions. Psychometrika, 52(3), 345-370. https://doi.org/10.1007/BF022 94361

Browman, H. I., Boxaspen, K., \& Kuhn, P. (2004). The effect of light on the settlement of the salmon louse, Lepeophtheirus salmonis, on Atlantic salmon, Salmo salar L. Journal of Fish Diseases, 27(12), 701- 708. https://doi.org/10.1111/j.1365- 2761.2004.00592.x

Cardon, M., Loot, G., Grenouillet, G., \& Blanchet, S. (2011). Host characteristics and environmental factors differentially drive the burden and pathogenicity of an ectoparasite: A multilevel causal analysis. Journal of Animal Ecology, 80(3), 657-667. https://doi. org/10.1111/j.1365- 2656.2011.01804.x

Combes, C. (2001). Parasitism: The ecology and evolution of intimate interactions. University of Chicago Press.

Copp, G., \& Garner, P. (1995). Evaluating the microhabitat use of fresh- water fish larvae and juveniles with point abundance sampling by electrofishing. Folia Zoologica, 44(2), 145- 158.

da Silva, R. C., \& Langoni, H. (2009). Toxoplasma gondii: Host- parasite interaction and behavior manipulation. Parasitology Research, 105(4), 893-898. https://doi.org/10.1007/s0043 6- 009- 1526- 6

Decaestecker, E., De Meester, L., \& Ebert, D. (2002). In deep trouble: Habitat selection constrained by multiple enemies in zooplankton. Proceedings of the National Academy of Sciences of the United States of America, 99(8), 5481- 5485. https://doi.org/10.1073/pnas.08254 3099

Dormann, C. F., McPherson, J. M., Araújo, M. B., Bivand, R., Bolliger, J., Carl, G., Davies, R. G., Hirzel, A., Jetz, W., Daniel Kissling, W., Kühn, I., Ohlemüller, R., Peres- Neto, P. R., Reineking, B., Schröder, B., M. Schurr, F., \& Wilson, R. (2007). Methods to account for spatial autocorrelation in the analysis of species distributional data: A review. Ecography, 30(5), 609-628. https://doi. org/10.1111/j.2007.0906- 7590.05171.x

Fellous, S., Quillery, E., Duncan, A. B., \& Kaltz, O. (2011). Parasitic infection reduces dispersal of ciliate host. Biology Letters, 7(3), 327- 329. https://doi.org/10.1098/rsbl.2010.0862 
Fryer, G. (1982). The parasitic Copepoda and Branchiura of British freshwater fishes. A handbook and key. Freshwater Biological Association.

Gautret, P., Deharo, E., Tahar, R., Chabaud, A. G., \& Landau, I. (1995). The adjustment of the schizogonic cycle of Plasmodium chabaudi chabaudi in the blood to the circadian rhythm of the host. Parasite, 2(1), 69- 74. https://doi.org/10.1051/paras ite/199502 1069

Hall, M. D., \& Ebert, D. (2012). Disentangling the influence of parasite genotype, host genotype and maternal environment on different stages of bacterial infection in Daphnia magna. Proceedings of the Royal Society B: Biological Sciences, 279(1741), 3176- 3183. https:// doi.org/10.1098/rspb.2012.0509

Hallett, S. L., \& Bartholomew, J. L. (2008). Effects of water flow on the infection dynamics of Myxobolus cerebralis. Parasitology, 135(3), 371-384. https://doi.org/10.1017/S0031 182007003976

Hjulstrom, F. (1935). Study of the morphological activity of rivers as illustrated by river Fyris. Bulletin of the Geological Institution of the University of Upsala, 25, 221- 527.

Hoberg, E. P., Agosta, S. J., Boeger, W. A., \& Brooks, D. R. (2015). An integrated parasitology: Revealing the elephant through tradition and invention. Trends in Parasitology, 31(4), 128- 133. https://doi. org/10.1016/j.pt.2014.11.005

Hughes, D. P., Brodeur, J., \& Thomas, F. (2012). Host manipulation by parasites. Oxford University Press.

Jennett, A. L., Smith, F. D., \& Wall, R. (2013). Tick infestation risk for dogs in a peri- urban park. Parasites \& Vectors, 6(1), 358. https://doi. org/10.1186/1756- 3305- 6- 358

Karvonen, A., SeppäLä, O., \& Valtonen, E. T. (2004). Parasite resistance and avoidance behaviour in preventing eye fluke infections in fish. Parasitology, 129(2), 159-164. https://doi.org/10.1017/S0031 182004005505

Keith, P., Persat, H., Feunteun, É., \& Allardi, J. (2011). Les poissons d'eau douce de France. Biotope.

Kuris, A. M., Goddard, J. H. R., Torchin, M. E., Murphy, N., Gurney, R., \& Lafferty, K. D. (2007). An experimental evaluation of host specificity: The role of encounter and compatibility filters for a rhizocephalan parasite of crabs. International Journal for Parasitology, 37(5), 539- 545. https://doi.org/10.1016/j.ijpara.2006.12.003

Lacey, E. S., Ray, A., \& Cardé, R. T. (2014). Close encounters: Contributions of carbon dioxide and human skin odour to finding and landing on a host in Aedes aegypti: Response of Aedes aegypti to $\mathrm{CO}_{2}$ and human foot odour. Physiological Entomology, 39(1), 60- 68. https://doi. org/10.1111/phen.12048

Lawrence, P. O. (1981). Host vibration? A cue to host location by the parasite, Biosteres longicaudatus. Oecologia, 48(2), 249- 251. https://doi. org/10.1007/BF003 47971

Lawson, A. B. (2010). Hotspot detection and clustering: Ways and means. Environmental and Ecological Statistics, 17(2), 231- 245. https://doi. org/10.1007/s1065 1- 010- 0142- z

Loot, G., Poulet, N., Brosse, S., Tudesque, L., Thomas, F., \& Blanchet, S. (2011). Determinants of life- history traits in a fish ectoparasite: A hierarchical analysis. Parasitology, 138(7), 848-8 57. https://doi. org/10.1017/S0031 $18201100014 \mathrm{X}$

Loot, G., Poulet, N., Reyjol, Y., Blanchet, S., \& Lek, S. (2004). The effects of the ectoparasite Tracheliastes polycolpus (Copepoda: Lernaeopodidae) on the fins of rostrum dace (Leuciscus leuciscus burdigalensis). Parasitology Research, 94(1), 16- 23. https://doi. org/10.1007/s0043 6- 004- 1166- 9

Lootvoet, A., Blanchet, S., Gevrey, M., Buisson, L., Tudesque, L., \& Loot, G. (2013). Patterns and processes of alternative host use in a generalist parasite: Insights from a natural host- parasite interaction. Functional Ecology, 27(6), 1403- 1414. https://doi. org/10.1111/1365- 2435.12140

Marcogliese, D. J. (2016). The Distribution and abundance of parasites in aquatic ecosystems in a changing climate: More than just temperature. Integrative and Comparative Biology, 56(4), 611- 619. https:// doi.org/10.1093/icb/icw036

Mathieu- Bégné, E., Blanchet, S., Rey, O., Scelsi, O., Poesy, C., Marselli, G., \& Loot, G. (2021). Resources for “A finescale analysis reveals microgeographic hotspots maximizing infection rate between a parasite and its fish host". Figshare Digital Repository, https://doi. org/10.6084/m9.figsh are.14473467

Mathieu- Bégné, E., Loot, G., Mazé- Guilmo, E., Mullet, V., Genthon, C., \& Blanchet, S. (2021). Combining species distribution models and population genomics underlines the determinants of range limitation in an emerging parasite. Ecography, 44(2), 307- 3019. https:// doi.org/10.1111/ecog.05301

Mazé- Guilmo, E. (2016). Etude du potentiel de colonisation des parasites: Une approche intégrative. Thèse de Doctorat. Université Paul Sabatier (Toulouse III). 
Mikheev, V. N. (2011). Monoxenous and heteroxenous fish parasites manipulate the behavior of their hosts in different ways. Biology Bulletin Reviews, 1(5), 446-457. https://doi.org/10.1134/S2079 086411050045

Mikheev, V. N., Pasternak, A. F., \& Valtonen, E. T. (2015). Behavioural adaptations of argulid parasites (Crustacea: Branchiura) to major challenges in their life cycle. Parasites \& Vectors, 8(1), Article 1. https:// doi.org/10.1186/s1307 1- 015- 1005- 0

Morand, S., \& Deter, J. (2007). Parasitisme et régulation des populations hôtes (pp. 13- 56). Ecologie et Évolutin Des Systèmes Parasités, De Boeck.

Murphy, T. M., O’Connell, J., Berzano, M., Dold, C., Keegan, J. D., McCann, A., Murphy, D., \& Holden, N. M. (2012). The prevalence and distribution of Alaria alata, a potential zoonotic parasite, in foxes in Ireland. Parasitology Research, 111(1), 283-290. https://doi. org/10.1007/s0043 6- 012- 2835- 8

Pasch, B., Bolker, B. M., \& Phelps, S. M. (2013). Interspecific dominance via vocal interactions mediates altitudinal zonation in neotropical singing mice. The American Naturalist, 182(5), 161- 173. https://doi. org/10.1086/673263

Pasternak, Z. (2004). Host location by larvae of a parasitic barnacle: Larval chemotaxis and plume tracking in flow. Journal of Plankton Research, 26(4), 487- 493. https://doi.org/10.1093/plank t/fbh040 Paull, S. H., Song, S., McClure, K. M., Sackett, L. C., Kilpatrick, A. M., \& Johnson, P. T. (2012). From superspreaders to disease hotspots: Linking transmission across hosts and space. Frontiers in Ecology and the Environment, 10(2), 7582. https://doi. org/10.1890/110111

Poulin, R. (1993). The disparity between observed and uniform distributions: A new look at parasite aggregation. International Journal for Parasitology, 23(7), 937-944. https://doi. org/10.1016/0020- 7519(93)90060 - C

Poulin, R. (1995a). Clutch Size and egg size in free- living and parasitic copepods: A comparative analysis. Evolution, 49(2), 325. https://doi. org/10.2307/2410343

Poulin, R. (1995b). Evolution of parasite life history traits: Myths and reality. Parasitology Today, 11(9), $342-345$. https://doi. org/10.1016/0169-4758(95)80187 - 1

Poulin, R., \& FitzGerald, G. J. (1989). Risk of parasitism and microhabitat selection in juvenile sticklebacks. Canadian Journal of Zoology, 67(1), 14- 18. https://doi.org/10.1139/289- 003

R Core Team. (2020). R: A language and environment for statistical computing. R Foundation for Statistical Computing. https://www.R- proje ct.org/

Ramirez- Sierra, M. J., Herrera- Aguilar, M., Gourbière, S., \& Dumonteil, E. (2010). Patterns of house infestation dynamics by non- domiciliated Triatoma dimidiata reveal a spatial gradient of infestation in rural villages and potential insect manipulation by Trypanosoma cruzi. Tropical Medicine \& International Health, 15(1), 77-8 6. https://doi. org/10.1111/j.1365-3156.2009.02422.x

Rea, J. G., \& Irwin, S. W. B. (1994). The ecology of host- finding behaviour and parasite transmission: Past and future perspectives. Parasitology, 109(S1), S31- S39. https://doi.org/10.1017/S0031 182000085061 Samsing, F., Solstorm, D., Oppedal, F., Solstorm, F., \& Dempster, T. (2015). Gone with the flow: Current velocities mediate parasitic infestation of an aquatic host. International Journal for Parasitology, 45(8), 559565. https://doi.org/10.1016/j.ijpara.2015.03.006

Sutherland, B. J. G., Jantzen, S. G., Sanderson, D. S., Koop, B. F., \& Jones, S. R. M. (2011). Differentiating sizedependent responses of juvenile pink salmon (Oncorhynchus gorbuscha) to sea lice (Lepeophtheirus salmonis) infections. Comparative Biochemistry and Physiology Part D: Genomics and Proteomics, 6(2), 213223. https:// doi.org/10.1016/j.cbd.2011.04.001

Thamm, S., Kalko, E. K. V., \& Wells, K. (2009). Ectoparasite infestations of hedgehogs (Erinaceus europaeus) are associated with small- scale landscape structures in an urban-suburban environment. EcoHealth, 6(3), 404413. https://doi.org/10.1007/s1039 3-009- 0268- 3

Theron, A., \& Combes, C. (1995). Asynchrony of infection timing, habitat preference, and sympatric speciation of Schistosome parasites. Evolution, 49, 372- 375. https://doi.org/10.1111/j.1558- 5646.1995. tb022 49.x

van Dijk, J. G. B., Kleyheeg, E., Soons, M. B., Nolet, B. A., Fouchier, R. A. M., \& Klaassen, M. (2015). Weak negative associations between avian influenza virus infection and movement behaviour in a key host species, the mallard Anas platyrhynchos. Oikos, 124(10), 1293-1303. https://doi.org/10.1111/oik.01836 
Ward, S. A., Leather, S. R., Pickup, J., \& Harrington, R. (1998). Mortality during dispersal and the cost of hostspecificity in parasites: How many aphids find hosts? Journal of Animal Ecology, 67(5), 763- 773. https://doi.org/10.1046/j.1365-2656.1998.00238.x

Williams, J. A., \& Esch, G. W. (1991). Infra- and component community dynamics in the pulmonate snail Helisoma anceps, with special emphasis on the hemiurid trematode Halipegus occidualis. Journal of Parasitology, 77(2), 246. https://doi.org/10.2307/3283091

Wolinska, J., \& King, K. C. (2009). Environment can alter selection in host- parasite interactions. Trends in Parasitology, 25(5), 236- 244. https://doi.org/10.1016/j.pt.2009.02.004

Zimmermann, M. R., Luth, K. E., \& Esch, G. W. (2016). Microhabitat differences in the benthic substrata affect parasitism in a pulmonate snail host, Helisoma anceps. Journal of Parasitology, 102(3), 306- 311. https://doi.org/10.1645/15- 763

\section{SUPPORTING INFORMATION}

Additional supporting information may be found in the online version of the article at the publisher's website. 

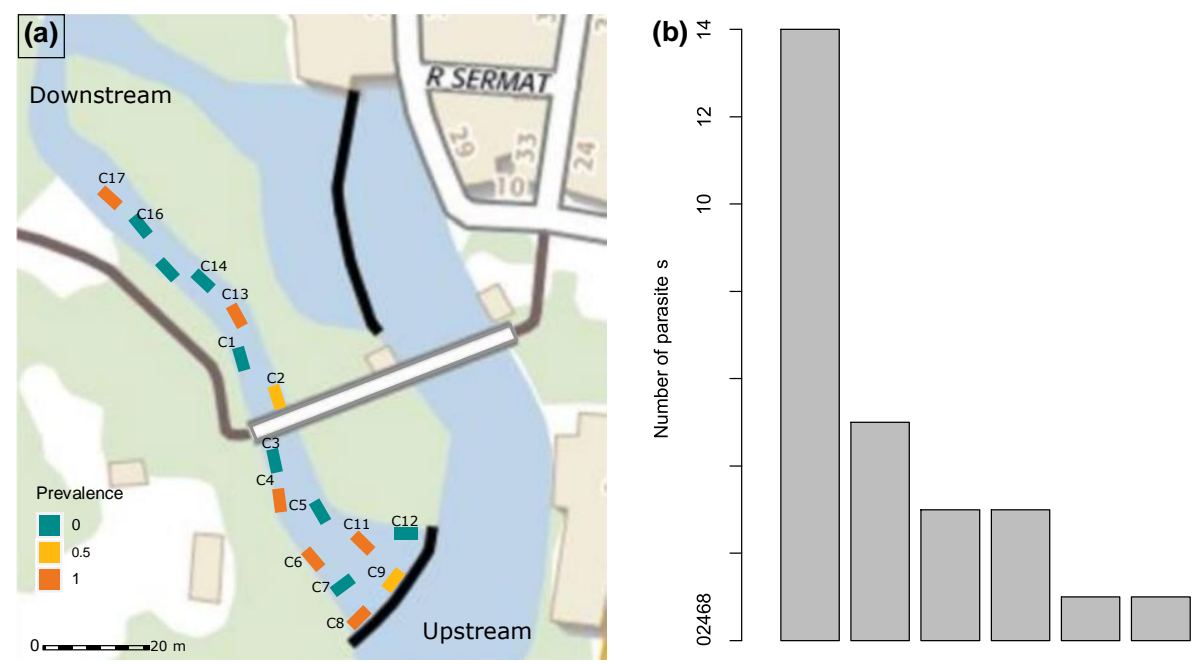

\section{C8 C6 C11 C13 C2 C9 C1 C12 C14 C15 C16 C3 C5 C7}
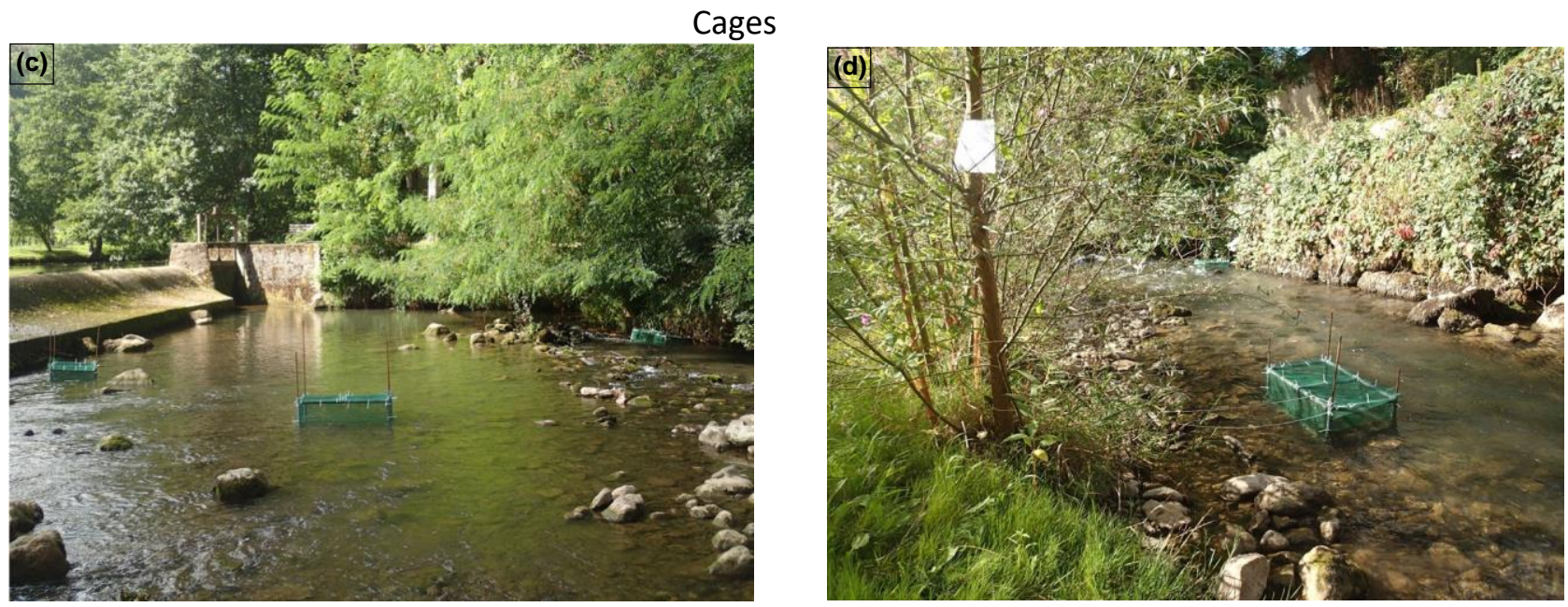
FIGURE 1 Panel displaying (a) the position of each cage (rectangles) along with the prevalence recorded at the end of the caging experiment, (b) the distribution of the total number of Tracheliastes polycolpus per cage (c and d) pictures of cages set in different habitats within the river section 

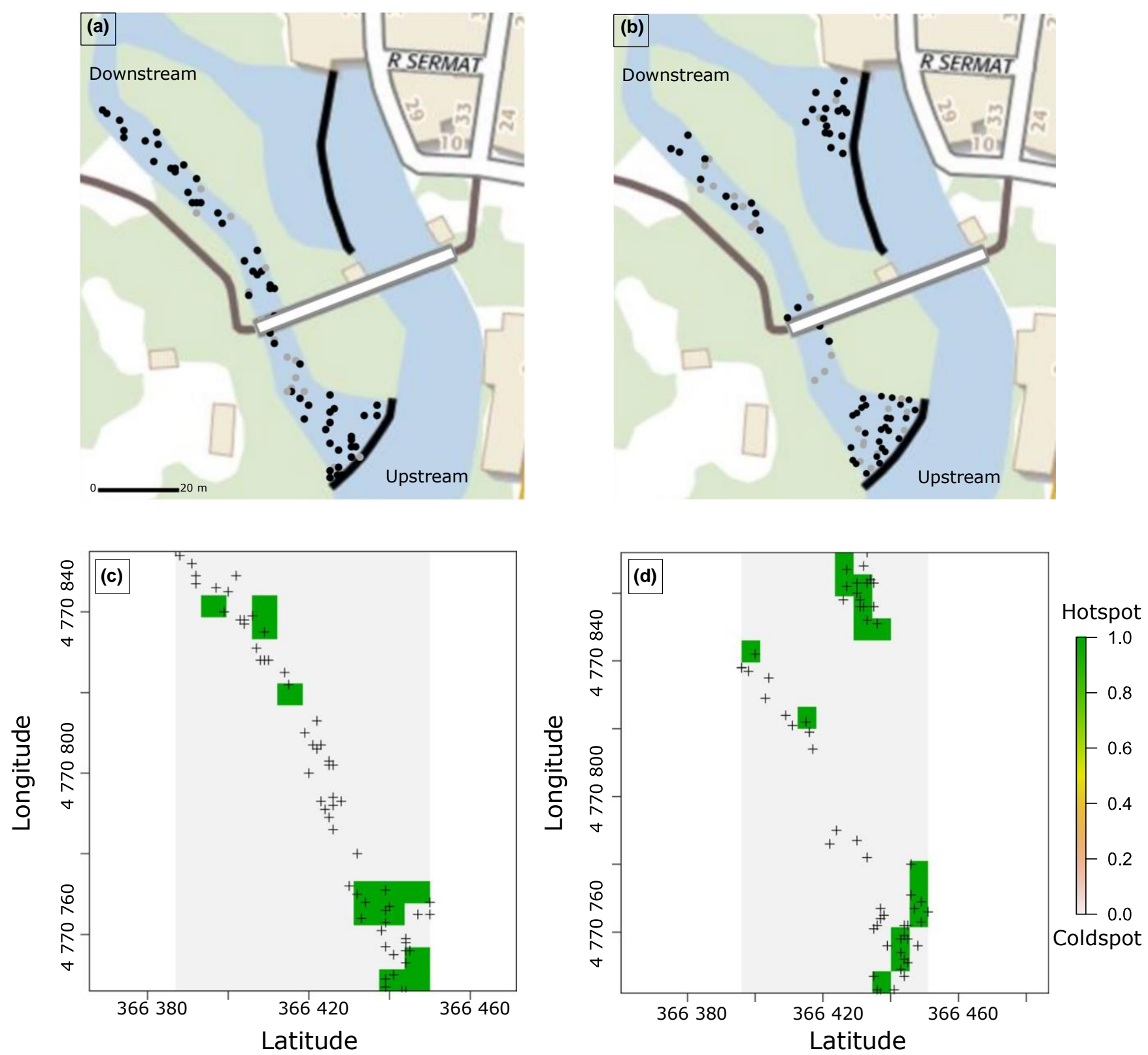

FIGURE 2 Spatial distribution of the microhabitats sampled during the empirical approach. Maps (a and b) display all microhabitats sampled by electrofishing containing potential hosts (Phoxinus phoxinus the European minnow and Gobio occitaniae, the Occitan gudgeon, black dots) or not (no fish or other fish species, grey dots) in 
2017 and 2018 respectively. Black lines with a larger width refer to weirs. Maps (c and d) display the results of the joint count analysis in 2017 and 2018 respectively. Black crosses refer to microhabitats with hosts only and green areas are predicted hotspots of infections (i.e. zones where parasitized hosts are significantly aggregated in space) 

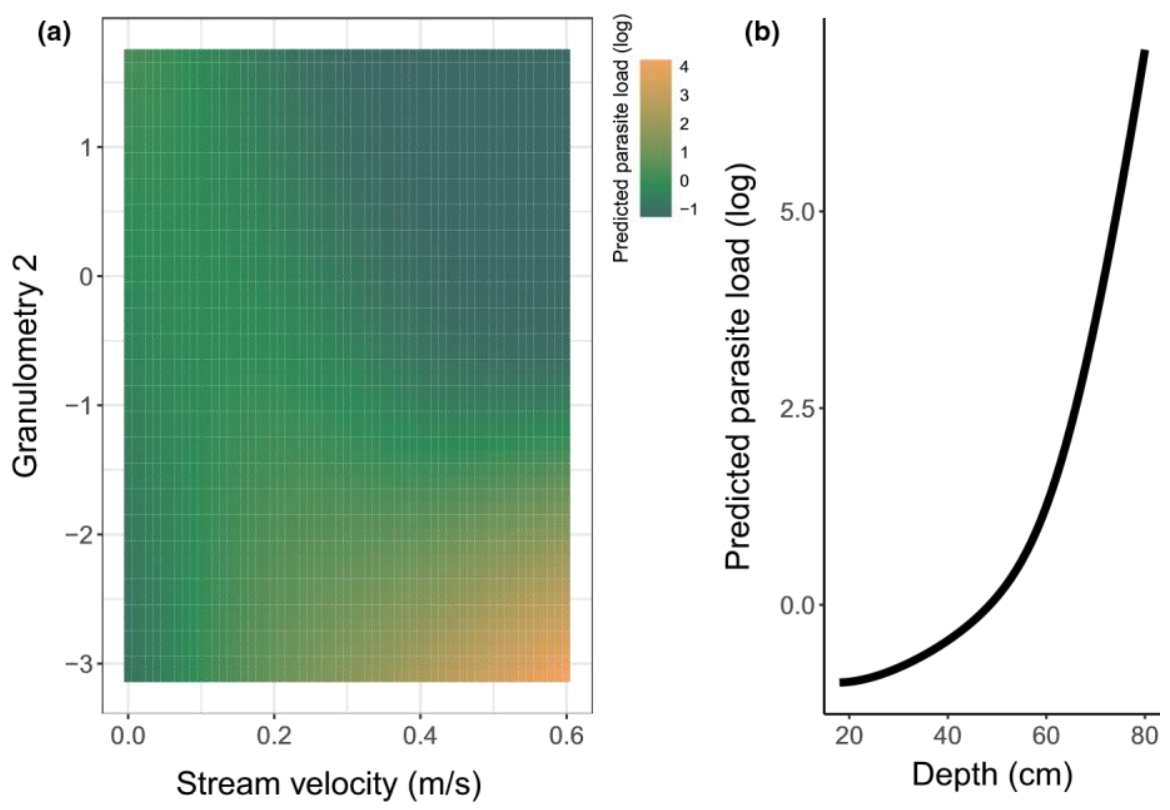

FIGURE 3 Predicted parasite load (log scaled) according to (a) the interaction between stream velocity ( $\mathrm{m} / \mathrm{s}$ ) and the second synthetic variable of substrate composition and according to (b) water depth $(\mathrm{cm})$ in the caging experiment. In the caging experiment, encaged rostrum dace Leuciscus burdigalensis were naturally exposed to the parasite Tracheliastes polycolpus 


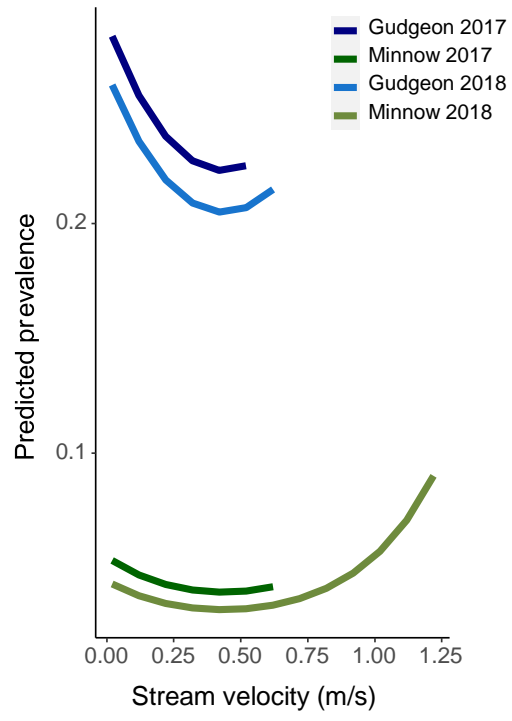

FIGURE 4 Predicted Tracheliastes polycolpus prevalence according to stream velocity $(\mathrm{m} / \mathrm{s})$ in the empirical approach. Relationship is shown for each year (2017 and 2018) and each host species: gudgeon Gobio occitaniae and minnow Phoxinus phoxinus 
TABLE 1 Results of the model selection approach for the caging experiment involving encage rostrum dace Leuciscus burdigalensis naturally exposed to the parasite Tracheliastes polycolpus. Best models $(\Delta \mathrm{AIC}<2)$ linking prevalence to microhabitat variables are displayed according to the AIC decreasing order. For each variable the estimates are shown. NA is denoted in place of the estimate when a variable in not retained in the model. Granulo. stands for Granulometry

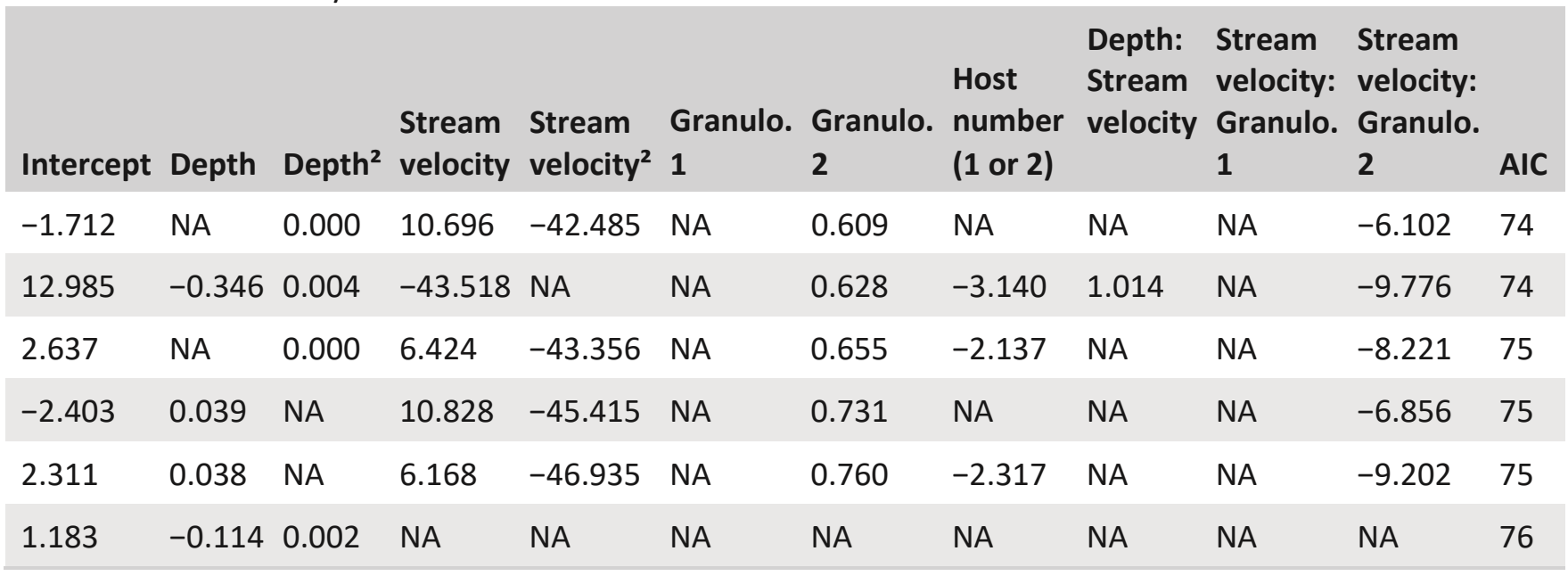


TABLE 2 Results of the model selection approach for the empirical approach involving wild Occitan gudgeons Gobio occitaniae and European minnows Phoxinus phoxinus naturally exposed to the parasite Tracheliastes polycolpus. Best models $(\triangle \mathrm{AIC}<2)$ linking parasite prevalence to microhabitat variables are displayed according to the AIC decreasing order. For each variable the estimates are shown. NA is denoted in place of the estimate when a variable is not retained in the model. Granule. stands for Granulometry

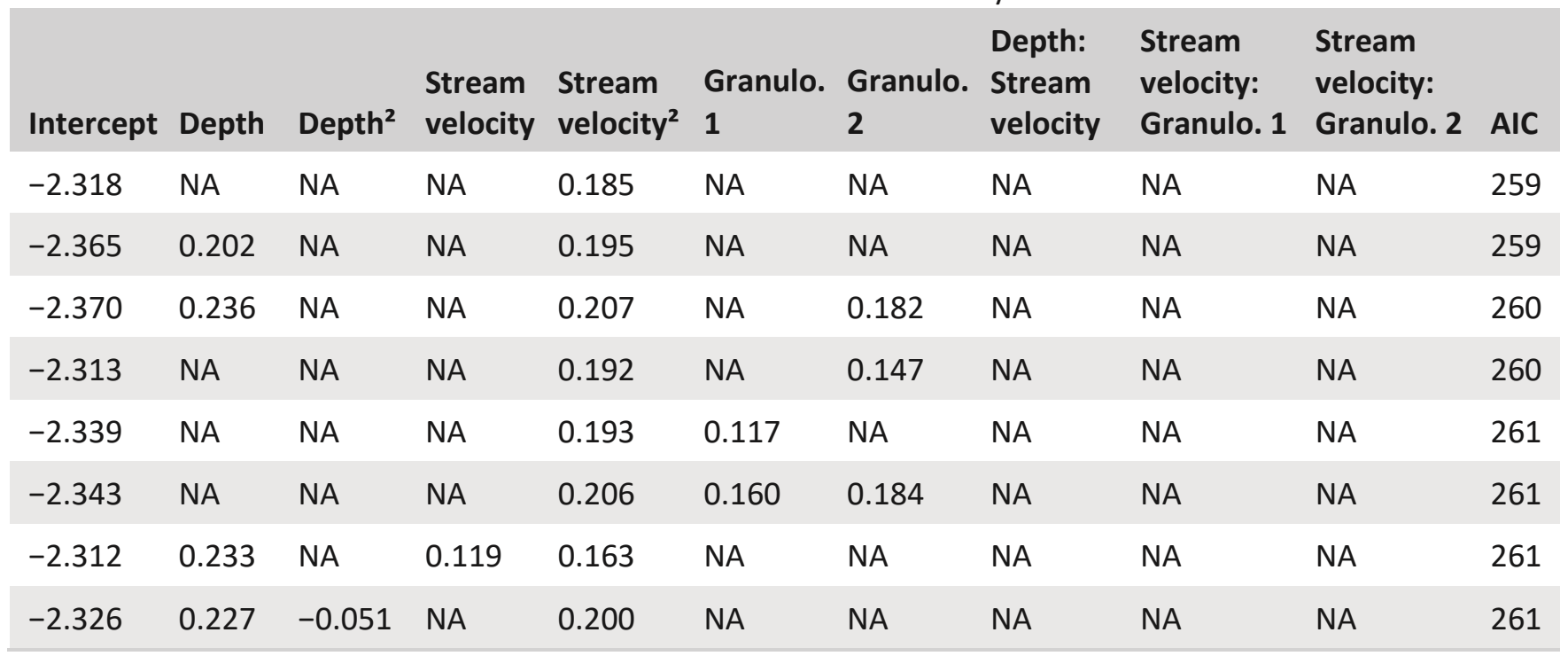

